\title{
O PACIENTE PORTADOR DE MARCA-PASSO CARDÍACO E A REPERCUSSÃO EM SEU ESTILO DE VIDA
}

\author{
Cardiac Pacemaker Bearer Pacient and the \\ Repercussion in the Lifestyle \\ El Paciente Portador de Marcapaso Cardíaco y la \\ Repercusión en su Estilo de Vida
}

Mirna Albuquerque Frota

Patrice Vale Falcão

Zélia Maria de Sousa Araújo Santos

\section{Resumo}

Objetivou-se discutir a repercussão no estilo de vida do paciente portador de marca-passo. Os informantes foram sete usuários que se submeteram ao implante de marca-passo definitivo no Hospital de Messejana - CE, Brasil, de maio a junho de 2004. A análise dos dados foi desenvolvida a partir da categorização dos conteúdos das entrevistas, emergindo como resultado duas categorias temáticas: condições de vida mediante a descoberta da doença e repercussão do autocuidado no estilo de vida no contexto da promoção da saúde. Conclui-se que há necessidade de formar equipes multiprofissionais para atuar com estratégias em educação em saúde, ampliando e divulgando a utilização do marca-passo definitivo, e objetivando a adesão destas pessoas à prática do autocuidado.

Palavras-chave: Estilo de Vida. Marca-Passo Artificial. Autocuidado. Educação em Saúde.

\section{Abstract}

This study aimed to discuss the repercussion in the lifestyle of the pacemaker bearer patient. The informants were seven patients that were submitted to the definitive pacemaker implant in the Messejana Hospital - Ceára (Brazil), from May to June 2004. The data analysis was developed from the categorization of the interviews contents, emerging as a result two thematic categories: life conditions because of the disease discovery and self-care repercussion in the lifestyle change in the context of the health promotion. It is concluded the need of forming multi-professional teams to act in strategies in Health Education, enlarging and publishing the use of the definitive pacemaker, aiming at these people's adherence for the similar self-care.

\section{Keywords:}

Lifestyle. Pacemaker, Artificial. Self-care. Health Education.

\section{Resumen}

El objetivo fue discutir la repercusión en el estilo de vida del paciente portador de marcapaso. Los informantes fueron siete usuarios que se sometieron al implante de marcapaso definitivo en el Hospital de Messejana - Ceará (Brasil), entre mayo y junio de 2004. El análisis de los datos se desarrolló a partir de la categorización de los contenidos de las entrevistas, surgiendo como resultado dos categorías temáticas: Condiciones de vida mediante el descubrimiento de la enfermedad y repercusión del autocuidado en el estilo de vida en el contexto de la promoción de la salud. Se concluyó que existe la necesidad de formar equipos multiprofesionales para actuar con estrategias en Educación para la Salud, ampliando y divulgando la utilización del marcapasos definitivo, con el objetivo de que estas personas adhieran a la práctica del autocuidado.

Palabras clave: Estilo de Vida. Marcapaso Artificial. Autocuidado. Educación en Salud. 


\section{INTRODUÇÃO}

Atualmente, milhares de pessoas em todo o mundo submetem-se a um procedimento cirúrgico para implante de marca-passo mecânico cardíaco, objetivando aumentar a sobrevida. Ao longo das últimas décadas, os avanços tecnológicos permitiram o desenvolvimento de aparelhos capazes de propiciar a quantidade e a qualidade de vida das pessoas, adequando a sua freqüência à necessidade metabólica do portador, trabalhando de forma semelhante ao marca-passo cardíaco natural, prolongando vidas e permitindo a realização de atividades diárias, anteriormente restritas. A estimulação elétrica é considerada um meio de auxílio que visa à melhoria do estilo de vida' .

A atividade cardíaca de um coração saudável varia de 60 a 80 batimentos por minuto. Quando por algumas vezes o coração apresenta falha na condução do impulso elétrico, deixando de produzir os batimentos cardíacos adequados, ele se transforma em um "coração lento" por curtos ou constantes períodos².

Neste contexto, é fundamental o conhecimento do funcionamento do sistema, bem como um acompanhamento sistemático, para que sejam realizadas freqüentes avaliações do marca-passo e, assim, garantir o bem-estar e favorecer uma condição de vida adequada. Mediante experiências vivenciadas em um hospital público do Estado do Ceará, observou-se que as pessoas não estavam preparadas para o implante desse aparelho, no sentido de adotar uma prática eficaz de autocuidado. São freqüentes os retornos em decorrência de transtornos oriundos do déficit de conhecimento relacionado, principalmente, ao funcionamento do aparelho nas atividades da vida cotidiana, gerando insegurança e medo.

As complicações mais comuns, como extrusão do gerador por infecção na incisão cirúrgica e edema localizado, conduziam a reinternação para tratamento e/ou até mesmo um reimplante do aparelho. Outras situações geravam desequilíbrios psicobiológicos e socioespiritual. Portanto, faz-se necessário avaliar o conhecimento e a prática do autocuidado em relação ao uso do marca-passo definitivo, já que, uma vez implantado, a pessoa deverá aprender a conviver com este aparelho, adaptando-o ao estilo de vida.

0 cuidar é o desenvolvimento de ações, atitudes e comportamentos com base no conhecimento científico. 0 cuidado configura-se em promover, manter ou recuperar a dignidade humana ${ }^{3}$. Observa-se a necessidade do conhecimento sobre a situação, de questionamento e reflexão sobre a condição, para que se identifique o processo de cuidar, obtendo-se meios para que se realize e execute o cuidado, com base nos valores e sentimentos em relação à situação de vida atual.

Na prática diária, a adoção de condutas inerentes ao estilo de vida apresentado por portadores de marca-passo caracteriza o déficit de autocuidado, que impossibilita a conquista de qualidade de vida. Portanto, conduzir essas pessoas a estabelecer laços com a nova vida viabilizaria a reflexão crítica, a aceitação e a adaptação de estilo de vida adequado, e isso consiste na responsabilidade da equipe de saúde, em particular do enfermeiro, que é educador em saúde de formação. Por isso, todo profissional de saúde deve ser um educador libertador, transformador e emancipador ${ }^{4}$, assumindo, assim, o papel fundamental na vida das pessoas, desmistificando questões que dificultam a sobrevivência.

Do ponto de vista fisiológico, o homem é capaz de aderir às mudanças diante da realidade que Ihe foi imposta, obviamente quando percebe que a ação transformadora objetiva uma esperança de vida melhor ${ }^{5}$. Compreender ou não o funcionamento do aparelho pode prejudicar o modo de viver na relação consigo mesmo, na sociedade e no sentido da vida. Com base neste pressuposto, compreende-se que a educação em saúde é um recurso estratégico essencial na processualidade da promoção da saúde, não só no aspecto da comunicação social, mas também como uma combinação de vida que propicia a saúde.

Promover saúde é capacitar a comunidade para atuar na melhoria da sua qualidade de vida e saúde. Para tanto, o significado de viver bem e cuidar-se envolve entendimento, confiança e conscientização sobre o estado da pessoa. É nesse aspecto que a educação em saúde tem papel significativo na formação da ação humana, como caráter fisiológico, ideológico, político, histórico e social da vida.

Diante desta problemática, torna-se relevante a necessidade de reflexão diante dos valores humanos, culturais, econômicos e sociais dos portadores de marca-passo artificial (o ser humano possui o biológico) definitivo, diagnosticando as alterações no estilo de vida, decorrentes do implante desse artefato, para fins de implementação de estratégias educativas em saúde, que conduzam essas pessoas a executar eficazmente a prática do autocuidado.

Portanto, o presente estudo tem o objetivo de discutir a repercussão no estilo de vida do paciente portador de marca-passo.

\section{METODOLOGIA}

Estudo descritivo com abordagem qualitativa, que exigiu a obtenção de uma série de informaç̃̃es sobre a pessoa portadora de marca-passo e a repercussão no estilo de vida, caracterizando a descrição com exatidão da realidade a partir dos fatos e fenômenos. Dessa maneira, os aspectos epistemológicos existentes no contexto respeitaram o método e o caminho do fazer científico, como instrumento que possibilite 0 alcance destes objetivos.

A pesquisa foi realizada no Ambulatório de Marca-passo Cardíaco Permanente de um Hospital do Sistema Único de Saúde - SUS, de referência norte e nordeste no atendimento secundário e terciário aos usuários com doença do coração e do pulmão, situado em Fortaleza - Ceará. 0 ambulatório atendia, em média, seis pessoas por dia.

Foram selecionados sete clientes com idade entre 50 e 82 anos, com o diagnóstico de bloqueio atrioventricular total (BAVT), independentemente de sexo, estado civil, escolaridade, renda e crença, com condições físicas e emocionais para participar da pesquisa, e que não apresentassem outras doenças crônicas, uma vez que essas também alteram o estilo de vida das pessoas.

A coleta dos dados iniciou-se com a observação livre durante o procedimento de implante do marca-passo definitivo. 
Foram colhidos dados sobre o estado emocional e 0 comportamento durante o implante, registrados em um diário de campo e apresentados nas discussões das categorias que respondem ao questionamento da repercussão no estilo de vida do paciente portador de marca-passo. Após o procedimento cirúrgico, eram encaminhados à enfermaria, onde permaneciam por dois a três dias. Quando saíam de alta hospitalar, levavam a programação do primeiro retorno ao ambulatório de marca-passo definitivo. 0 primeiro retorno era para retirada dos pontos da incisão cirúrgica, e, cerca de um mês ou dois, o segundo retorno era para a avaliação periódica do funcionamento do aparelho. Nesse retorno foi aplicada a entrevista semi-estruturada com as seguintes questões norteadoras: Que cuidados adotou com a descoberta da doença? 0 senhor foi orientado sobre estes cuidados? Qual a repercussão do marca-passo no seu estilo de vida? A implantação do marca-passo trouxe mudança para a sua vida?

As entrevistas foram gravadas, transcritas, codificadas e, posteriormente, analisadas de acordo com a técnica de Bardin ${ }^{6}$, fundamentadas nas experiências dos sujeitos.

0 estudo foi realizado com base na Resolução N. ${ }^{\circ}$ 96/ 1996, do Conselho Nacional de Saúde - CNS, obedecendo aos aspectos éticos recomendados em pesquisas realizadas em seres humanos ${ }^{7}$. Houve um termo de consentimento livre e esclarecido, que foi assinado pelos sujeitos. A pesquisa foi aprovada pelo Comitê de Ética do referido Hospital.

\section{RESULTADOS E DISCUSSÃO}

De acordo com os depoimentos dos sujeitos, emergiram as seguintes categorias temáticas: condições de vida mediante a descoberta da doença, a prática do autocuidado, e a repercussão no estilo de vida.

\section{Cuidados mediante a descoberta da doença}

Considerando a complexidade dos sistemas do corpo humano e as possíveis fontes de doenças existentes, atreladas às mudanças de comportamento dos indivíduos nos tempos atuais, parece difícil diagnosticar uma doença com base em sinais e sintomas relatados. Estudos demonstram que manifestações clínicas apresentadas podem estar relacionadas a diferentes padrões de vida, capazes de propiciar sintomas que se tornam obscuros, por acreditar-se que as devidas manifestações podem ser resultantes do moderno estilo de vida, correlacionando-os a certos traços da personalidade e padrões de comportamento, provenientes da chamada supercivilização̊.

Outro fator evidenciado no comportamento, embora haja manifestações clínicas que diagnostiquem uma doença, seja ela qual for, é o processo de adoecimento que quase sempre é desprezado e até mesmo negado. De modo geral, a doença representa a interrupção do modo de viver, comprometendo, na maioria das vezes, as condições de vida e, conseqüentemente, a qualidade de vida, principalmente quando esta deixa seqüela ou dependência, como é o caso dos portadores de marca-passo definitivo.

Neste contexto, percebemos que as pessoas que têm indicação do uso do marca-passo definitivo, ao serem atendidos nos sistemas de saúde, apresentam sinais e sintomas clínicos de alteração na condução elétrica do coração, o que logo é confirmado por exames específicos, como o eletrocardiograma (ECG.), o ecocardiograma e o teste ergométrico. Mas os dados clínicos manifestados não significavam que estivessem apresentando problemas de origem cardíaca, já que os sinais e sintomas referidos, na sua concepção, poderiam estar associados à exaustão do dia-a-dia e/ou até mesmo a outras patologias, como a virose, o estresse, a labirintite, ou seja, não relacionados a comprometimentos cardíacos.

Eu não sentia nada... Só sentia assim... desânimo, tontura. (D1)

Eu sentia falta de ar, eu não podia fazer uma coisa que cansava rápido. Eu ficava parada. Também, quando ia deitar sentia meus pés inchados e falta de ar. (D2)

Eu sentia tontura, sentia uma batida muito forte no coração, só faltava sair pela boca, e a outra coisa, sentia cansaço pelas pernas, pelos pés, falta de ar. Senti várias vezes falta de ar e cansaço, ficava de noite sufocada. (D3)

Os sujeitos submetidos ao implante do marca-passo apresentavam alguns sintomas, tais como astenia, dispnéia, edema, tonturas e mal-estar, que os levavam a preocupar-se com que estivessem com algum problema de saúde, exceto uma doença cardíaca, pois os sintomas apresentados não se manifestavam no coração, o que habitualmente acontece quando se relaciona a doença ao órgão acometido.

Ao serem informados de que o problema estava relacionado ao coração, e, sobretudo à necessidade do implante do marcapasso definitivo, e sendo este um órgão vital, os sentimentos de insegurança, medo e impotência surgiam de imediato. Mas, tão logo compreendida a situação de risco, se entregavam ao tratamento cirúrgico com a esperança de uma vida nova.

...Fui ali no hospital, e o médico perguntou: e ai macho [expressão que denota coragem] o que é que tu tem? Quando ando, canso; ele disse: é o coração... Bateu o eletro e disse: tem que colocar o marca-passo e se não fizer isso hoje, amanhece morto... Então cheguei aqui. (D2)

.... Equando ele disse: vai ter que colocar o marca-passo... O médico falou pro meu filho, e logo ele ficou nervoso, ai ele perguntou: doutor como é essa implantação?. (D4)

...Eu fazia exame de coração e nunca deu, ai eu marquei um cardiologista e quando cheguei lá ele disse que eu não tinha mais condições de ir para casa... Que tinha que botar o marca-passo... Então chamei minha filha e ela foi comigo ao hospital. (D3)

Os depoimentos expressam a vontade, o desejo de permanecer vivendo e causaram uma reação adversa ao sofrimento, considerando que naquele momento a vida dependia do marcapasso, e, então, concordavam com o tratamento, convictos de que o implante era uma alternativa para mantê-los vivo.

\section{Repercussão no estilo de vida do paciente portador de marca-passo}

As dimensões da vida são impostas ao longo do tempo por circunstâncias inesperadas, devendo despertar reflexões e 
considerar as necessidades de mudanças no estilo de vida. Portanto, é possível vivenciarmos os desejos e sonhos almejados; é necessário, sobretudo, apreender a convivência diante das às mudanças que nos permitem alcançar a felicidade ${ }^{9}$. Mudar de vida pode ser uma decisão pessoal; na verdade, existe uma ansiedade de dar sentido à vida, procurando desenvolver práticas e atitudes que favoreçam o bem-estar biopsíquico e socioespiritual.

A aceitação e adaptação do estilo de vida ao uso do marcapasso fazem com que 0 indivíduo adquira um comportamento natural, capaz de estabelecer novas prioridades, pois aprenderá a conhecer e desenvolver estratégias que garantam a conquista de qualidade de vida. Para que ocorra essa transformação, no entanto, é preciso que se conheçam os obstáculos encontrados na vida, pois à medida que ocorre o seu desvendamento, mais facilmente serão obtidos recursos que facilitem viver razoavelmente.

As dimensões da vida variam de acordo com as pessoas, contextos e situações. Assim, conhecer os próprios valores e possibilidades constitui uma sabedoria, e o ser humano tem a potencialidade de controlar e transformar seu bem-estar, porque, quando percebe o negativo, na verdade, encontra o caminho para a qualidade de vida, e, então, surge a aceitação do processo de mudança. Quando não se traduzem os acontecimentos e fatos, no entanto, a vida torna-se inexpressiva ${ }^{10,11}$.

Mudou meu estilo de vida, aquilo que eu posso fazer eu faço, porque eu sei o que é certo, sei o que é bom, e eu vou procurando fazer só o que é bom. (D5)

Eu não posso trabalhar, não posso dirigir, não posso andar... Eu não posso agir como antes. Eu penso que pode ofender o marca-passo. (D6)

Até agora eu não tive problema, porque eu praticamente não estou me movimentando, estou me movimentando através de meus filhos. (D7)

Eu costumava varrer dentro de casa, essas coisas... lavar roupa, tudo isso eu fazia, agora não posso sair pela rua, eu saia muito, ia pra igreja, visitava hospitais, que eu sou da pastoral da saúde. (D8)

Percebe-se que ser feliz é viver com a naturalidade da vida, sem, no entanto, alterar a natureza desta. Assim, conhecendo a razão e as particularidades implicadas ao uso do marca-passo mais facilmente os portadores saberiam se comportar, estabelecendo limites e valores. Quando não se conhecem os mecanismos próprios, é possível que as pessoas se reprimam, pelo medo, pela emoção, pela projeção e indagação do desconhecido; e esta situação causa desequilibrio e desgaste emocional pelo temor do que poderá vir a acontecer.

A educação é essencial no processo de formação e transformação, pois é um exercício de reflexão da realidade, fundamentada nos conhecimentos adquiridos ao longo da vida, levando à autonomia. É, também, uma estratégia política utilizada na tentativa de alcançar programas de promoção e melhoria da qualidade de vida, mediante a valorização humana e a preservação de ambientes saudáveis. Portanto, promover a saúde não é tão complexo, desde que o indivíduo descubra o que lhe faz bem ou mal e respeite seus próprios limites, incorporando atitudes que protejam sua vida ${ }^{12,13}$. Assim a educação em saúde deve ser entendida como um processo de humanização, e o educador em saúde, como humanizador.

0 conhecimento é um processo de reconstrução próprio dos seres vivos. É a dinâmica viva capaz de interpretar os significados e as formas, e participar dessa realidade faz parte da própria experiência de vida, que, ao longo dos tempos, vai se aprofundando, sendo, portanto, uma ação biológica efetiva, pois se origina da busca do saber científico, procurando entender a natureza e a realidade dos fatos. 0 conhecimento é 0 ato de conhecer, saber e adquirir informações, extraídas das relações interpessoais, da cultura, das transformações e experiências de vida ${ }^{14}$.

Na saúde, o conhecimento é aplicado com vistas a prestar informações de forma individual e coletiva, objetivando assistir direta e indiretamente à população de modo a esclarecer a compreensão da tríade saúde-doença-cuidado. Estimula a uma prática de saúde saudável, considerando uma estratégia fundamental na educação e na promoção da saúde, pois, por meio da ciência, o indivíduo e a comunidade conseguem adquirir um padrão de vida adequado e mais saudável.

A idéia de promoção da saúde envolve o fortalecimento da capacidade individual e coletiva para lidar com a multiplicidade dos condicionantes da saúde ${ }^{15}$. A saúde é um fator essencial para o desenvolvimento humano e para se ter uma vida saudável, assegurando ao indivíduo 0 atendimento às suas necessidades básicas, assim como as mudanças de comportamento e estilo de vida são fatores responsáveis pela adequação dos cuidados de saúde.

As necessidades influenciam no comportamento humano, motivando o indivíduo a ampliar seus horizontes, buscando mais recursos que possibilitem uma qualidade de vida. Portanto, é preciso que as necessidades básicas dos seres humanos sejam atendidas, bem como a interação com o meio ambiente seja favorável, para que haja a auto-realização ${ }^{16}$.

0 desconhecimento da doença, sobretudo, dificulta 0 cotidiano, haja vista a impossibilidade de compreender e aceitar as necessidades de mudanças, a qual motiva a executar atividades de cuidados e valores inerentes ao processo da vida. Os significados no modo de viver são definidos pelos sujeitos.

Eu não pego em peso, não abro geladeira, não faço almoço, só faço mesmo me balançar numa rede...Não faço com medo, pode fazer mal... Minha casa é muito grande, eu ando só ao redor dela, no alpendre, não faço caminhada grande. (D10)

Não pego mais em nada...somente como e durmo...muito cuidado...penso em Deus e em ficar bom. (D4)

Não levantar peso, não passar roupa, não lavar, não ir para a cozinha porque o meu fogão é ligado na energia...Em casa não faço mais nada, só assim...ficando mais velha (risos). Não faço extravagância, até pra fechar uma porta, para não levantar o braço...Eu levo a vida assim.(D2)

Cuidado de ligar as coisas na energia... Fico em repouso, tenho medo de levantar o braço (direito), não faço esforço com medo de deslocar o marca-passo...Não posso fazer nada, então não faço. (D9) 
Observa-se nas falas que as mudanças ocorridas no estilo de vida eram resultantes da doença cardíaca, pois, sendo o coração um órgão fundamental e de simbolismo na vida humana, produziu reações de conflitos emocionais que thes fizeram privarse de levar uma vida normal. 0 déficit de conhecimento em relação ao marca-passo implicou um estilo de vida equivocado.

As doenças cardíacas, pela sua cronicidade, trazem repercussões de ordem emocional, impedindo as pessoas de retomarem as atividades diárias, e em muitos casos ocorre depressão, nervosismo, medo, dúvidas e desânimo. Estas alteraç̃̃es retratam verdadeiros desafios de retomada da vida, que geram angústia e medo de perdê-la, naturalmente pelo fato de o coração ser um órgão vital e possibilitar a adoção de cuidados. Essa situação surge quando essas pessoas não estão familiarizadas com os recursos de informações, e, contudo, não compreendem o funcionamento e acabam não desempenhando um comportamento de saúde desejado ${ }^{17,18,19}$. Contudo, a prática profissional centrada no cenário da educação em saúde, implementando condutas que conduzam o cliente à prática eficaz do autocuidado, com vista ao alcance do melhor nível de saúde e bem-estar, possibilita a conquista de qualidade de vida ${ }^{20}$.

\section{CONSIDERAÇÕES FINAIS}

Com base na importância do coração no ciclo vital e sendo este responsável pelos sentimentos de emoção, prazer, felicidade, sofrimento, decepção e angústia, o estudo revela que o indivíduo, quando acometido por uma patologia cardíaca, na sua interpretação, considera-se numa condição de risco de vida e, conseqüentemente, na iminência da morte.

Compreendendo que o marca-passo cardíaco definitivo é a alternativa de tratamento que visa aumentar a sobrevida e qualidade de vida dos dependentes do aparelho, foi possível

\section{Referências}

1. Brasil WW, Cruz DLM. Alterações nos hábitos de vida relatados por portadores de marcapasso definitivo. Reblampa 2000; 13(2): 97-113.

2. Martinelli J. Marcapasso: o coração no ritmo da vida. [on line] 2006 [citado 12 set 2006]. Disponível em: <http:// www.guiasaudeoncine.com.br/repor/marcapasso.htm>.

3. Waldow VR. Cuidado humano: o resgate necessário. Porto Alegre (RS): Sagra; 1999.

4. Santos ZMSA, Barroso MGT. A interdisciplinaridade na fundamentação da promoção da saúde. In: Barroso GT, Vieira NFC, Varela ZMV. Educação em saúde no contexto da promoção humana. Fortaleza(CE): Demócrito Rocha; 2003.

5. Freire P. Educação e mudança. Rio de Janeiro (RJ): Paz e Terra; 1987. 6. Bardin L. Análise de conteúdo. Lisboa(PT): Ed 70; 1977. perceber que a implantação deste muitas vezes provoca reações singulares de mudança de comportamento, que repercutem no estilo de vida dos portadores. Nessa direção, tenta-se, de forma reflexiva, enfatizar os conceitos de educação em saúde e promoção da saúde, como proposta fundamental para a prática adequada de autocuidado.

Desse modo, entende-se que a educação em saúde possibilita ao portador de marca-passo compreender e aceitar o processo de mudança, sendo capaz de desenvolver habilidades no cuidado que the permite alcançar melhor nível de saúde e, conseqüentemente, bem-estar biopsíquico e socioespiritual. É importante enfatizar que a idéia de comportamento está relacionada à identidade e à cultura dos seres humanos. As pessoas, ao viverem suas vidas, buscam associar o conhecimento com experiência de vida. Portanto, essa integração, quando não bem definida, causa distorção do entendimento, especialmente no âmbito da saúde-doença-cuidado, e, sobretudo, torna-se preocupante, pois, na tentativa de melhorar o nível de promoção da saúde, prejudica a qualidade e o estilo de vida.

Enfim, é necessário refletir na noção de que a vida depende do crescimento e desenvolvimento pessoal e cognitivo. Neste aspecto, destaca-se o fato de que a transformação do comportamento e estilo de vida dos portadores de marca-passo muito depende de como a presença do aparelho e da doença é interpretada e compreendida. 0 déficit de conhecimento, aliado às reações de sentimentos, resultaria na dificuldade de retornar à vida anterior à doença, adequando-a conforme a necessidade, o que geraria a adoção de um estilo de vida distorcido.

Conclui-se que há necessidade de formar equipes multiprofissionais para atuar com estratégias em educação em saúde, ampliando e divulgando a utilização do marcapasso definitivo, e objetivando a aderência destas pessoas à prática do autocuidado.

7. Ministério da Saúde (BR). Conselho Nacional de Saúde. Comissão Nacional de Ética em Pesquisa-CONEP. Resolução nº 196 / 96 sobre pesquisas envolvendo seres humanos. Brasília(DF); 1996.

8. Meltzer LE, Pinneo R, Kitcheell JR. Enfermagem na unidade coronária: bases, treinamento, prática. São Paulo (SP): Atheneu; 2001.

9. Richard C. Sua vida em primeiro lugar: como encontrar o equilíbrio entre sucesso profissional e qualidade de vida. Rio de Janeiro(RJ): Sextante; 2002.

10. Coelho Neto A, Araujo ALC. As dimensões da vida. Fortaleza (CE): ABC Fortaleza; 1998.

11. Santo Neto FE. Renovando atitudes: pelo espirito Hammed. Catanduva (SP): Boa Nova; 1997.

12. Reibnitz KS, Prado ML. Criatividade e relação pedagógica: em busca de caminhos para a formação do profissional crítico criativo. Rev Bras Enferm 2003; 56 (4):439-42. 
19. Cunha ICKO, Carmagnani MIS, Cornetta KV. Diagnóstico de Enfermagem em pacientes com hipertensão arterial em acompanhamento ambulatorial. Rev Paul Enferm 2002; 21(3): 269-79.

20. Santos ZMSA, Saraiva KRO, Costa CMV. Cliente portador de insuficiência cardíaca demandas de autocuidado. Esc Anna Nery Rev Enferm 2004; 8(2): 243-50.

\section{Sobre os Autores}

\section{Mirna Albuquerque Frota}

Universidade de Fortaleza - UNIFOR / Fortaleza - Ceará

Patrice Vale Falcão

Hospital de Messejana/MS/SUS/SESA / Fortaleza - Ceará

\section{Zélia Maria de Sousa Araújo Santos}

Universidade de Fortaleza - UNIFOR / Fortaleza - Ceará 